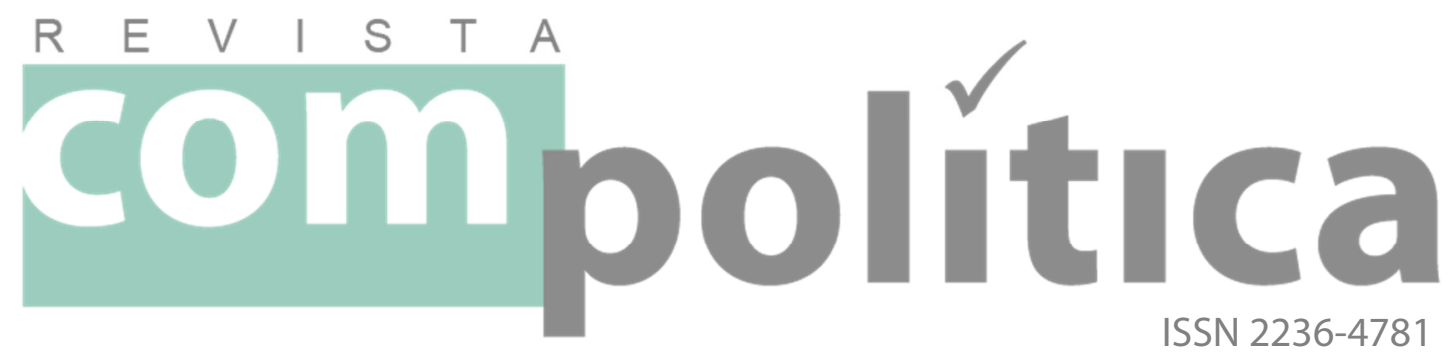

\title{
Campanha eleitoral nas redes sociais: estratégias empregadas pelos candidatos à Presidência em 2014 no Facebook
}

\section{[2014 Election campaign on social media: strategies employed by the presidential candidates on Facebook]}

MASSUCHIN, Michele Goulart

Doutora em Ciência Política. Professora do Departamento de Jornalismo da UFMA

[Phd in Political Science. Professor at the Journalism Department at Federal University of Maranhão] <mimassuchin@gmail.com>

\section{TAVARES, Camilla Quesada}

Mestre em Ciências Sociais Aplicadas. Professora do Departameto de Jornalismo da UEPG

[Master in Applied Social Sciences. Professor at the Journalism Department at State University of Ponta Grossa]

<camilla.tavares8@gmail.com>

\section{RESUMO}

Este artigo faz uma análise das estratégias que os três principais candidatos de 2014 - Dilma Rousseff, Marina Silva e Aécio Neves - empregam nas redes sociais, tomando-se como exemplo o Facebook. A análise tem como ponto de partida os modelos de Figueiredo et al. (1998) e Albuquerque (1999) para a observação das estratégias tradicionais e sugere a inclusão de estratégias tipicamente verificadas na internet (Willians e Gulati, 2013; Bor, 2013; Jensen e Dyrby, 2013). Utiliza-se como metodologia a análise de conteúde quantitativa para monitorar os 90 dias que compõem o primeiro turno da campanha eleitoral no Brasil, sendo a análise feita a partir de uma amostra de 803 postagens. Os resultados indicam que a estratégia de mobilização (online e offline), mesclada com a promoção de agenda, é o que predomina no Facebook.

Palavras-chave: Facebook; campanha eleitoral; redes sociais; análise de conteúdo.

Revista Compolítica 5 (2), 2015

Recebido em 27/08/2015

Aprovado em 25/10/2015

\section{ABSTRACT}

This article analyzes the strategies employed by the three leading candidates in the 2014 presidential elections - Dilma Rousseff, Marina Silva and Aécio Neves - on social media. The paper uses Facebook as analytical base. The analysis addresses the models proposed by Figueiredo et al. (1998) and Albuquerque (1999) to observe traditional strategies and suggest other strategies that are common on the Internet (Williams and Gulati, 2013; Bor, 2013; Jensen and Dyrby, 2013). Quantitative content analysis is the methodology used to analyze the 90 days that make up the first round of the election campaign in Brazil. A sample of 803 posts is evaluated. The results indicate that the mobilization strategy (online and offline), merged with the candidates' agenda, is predominant on Facebook.

Keywords: Facebook; electoral campaign; social media; content analysis. 


\section{Campanha eleitoral nas redes sociais: estratégias empregadas pelos candidatos à Presidência em 2014 no Facebook}

MASSUCHIN, Michele Goulart TAVARES, Camilla Quesada

om o objetivo de estudar a inserção das tecnologias nas
campanhas eleitorais, este artigo analisa como foi estruturada a propaganda dos três principais candidatos à Presidência da República em 2014 - Dilma Rousseff (PT); Aécio Neves (PSDB) e Eduardo Campos/Marina Silva (PSB) - no Facebook. O texto é centrado na identificação do uso que os candidatos e suas equipes fizeram desse novo espaço de campanha, principalmente no que diz respeito às estratégias de comunicação.

A partir das eleições de 2008 nos Estados Unidos e da proliferação das redes sociais (Gomes et al.., 2009), observa-se forte tendência em utilizar as ferramentas oferecidas pelo novo espaço durante o período eleitoral (Braga, Nicolás e Becher, 2013). O Facebook vem ganhando destaque continuamente e nas eleições de 2012 foi usado por $80 \%$ dos candidatos das capitais (Braga, Nicolás e Becher, 2013) e esteve mais presente que websites e outras redes sociais disponíveis. Além disso, quanto ao acesso por parte dos cidadãos, $76 \%$ dos brasileiros participam de redes sociais, segundo dados do Comitê Gestor da Internet no Brasil (2015). Neste mesmo sentido, segundo a Pesquisa Brasileira de Mídia 2015 (PBM, 2014), o Facebook é a rede mais utilizada pelos brasileiros, alcançando a preferência de $83 \%$ do total de respondentes. Embora a televisão continue sendo o veículo central utilizado pelos partidos e candidatos durante o período eleitoral e o meio mais utilizado pela população como fonte de 
informação (PBM, 2014), a internet passa a compor o cenário, contribuindo com o aumento da circulação de informações, oferecendo à elite política um espaço próprio de comunicação online (Holtz-Bacha et al., 2012) e também alterando a forma de interação entre candidatos e eleitores (Stromer-Galley, 2000).

Por meio desta pesquisa, pretende-se verificar de que maneira a campanha eleitoral online no Facebook foi estruturada e se há padrões entre as estratégias utilizadas pelos três candidatos. 0 estudo abrange o período de 90 dias de campanha para o primeiro turno (6 de julho a 5 de outubro), sendo que se optou por uma amostra dos posts publicados ao longo do período. Foram analisadas 283 postagens da campanha de Dilma Rousseff; 254 de Aécio Neves e 266 de Eduardo Campos/Marina Silva ${ }^{1}$. A metodologia empregada para a análise é a quantitativa de conteúdo, a partir de variáveis que elencam diferentes estratégias de campanha eleitoral.

As estratégias eleitorais empregadas nas páginas oficiais dos candidatos no Facebook é uma questão que perpassa os estudos sobre política e internet (Braga e Becher, 2013). A partir da literatura que trata das estratégias de campanha online, apresentam-se duas hipóteses: (1) os três candidatos usam o espaço para mobilizar o eleitor, reenergizando as bases da organização política e estimulando o engajamento, seja ele offline (em outras esferas de campanha) ou online (especificamente por meio da internet) como apontam Willians e Gulati (2013) e Bor (2013); (2) o Facebook tem o papel, também, de disseminar informação sobre a campanha,

\footnotetext{
${ }^{1}$ Aplicou-se a formula para amostras finitas, considerando o erro padrão de $5 \%$ e o índice de confiabilidade de $95 \%$. Em função das diferenças quantitativas para os três candidatos, utilizou-se uma amostra para cada candidato. Após finalizada a coleta, os três bancos foram agrupados para viabilizar os resultados comparativos. Para mais detalhes, ver o tópico sobre a metodologia.
} 
principalmente no que refere à agenda diária dos candidatos (Bor, 2013).

O artigo está dividido em três partes. Os primeiros dois tópicos, ambos de cunho teórico, embasam a discussão sobre a utilização da internet como espaço de campanha, bem como as diferentes estratégias de comunicação eleitoral já apresentadas pela literatura. $\mathrm{Na}$ sequência, dedica-se um tópico para a apresentação da metodologia e, posteriormente, faz-se a discussão da análise empírica dos dados. Por fim, apresentam-se as conclusões.

\section{0 alcance das redes sociais nas campanhas $e$ as potencialidades eleitorais}

As campanhas na internet têm se tornando objeto de interesse e relevância no campo da pesquisa em comunicação política, inclusive com aumento considerável da atenção dos pesquisadores nos últimos anos, em especial no Brasil (Aldé, Chagas e Santos, 2013). Ainda que o uso das redes sociais não substitua o papel do financiamento das campanhas e tampouco o uso da televisão como meio de maior expressão, tanto a pesquisa de Aggio e Reis (2015) quanto de Braga e Becher (2013) identificaram que o Facebook foi a rede digital mais utilizada nas campanhas de 2012 - em âmbito proporcional e majoritário. Ressalta-se, porém, que apesar da sua centralidade, o uso intenso da internet não assegura, necessariamente, bons resultados no pleito (Braga e Becher, 2013). Portanto, estuda-se as redes e o uso da internet como uma ferramenta complementar aos meios tradicionais, principalmente como fonte de informação e, consequentemente, munida de estratégias de comunicação. 
As redes sociais, além de difundirem conteúdo direto dos partidos e candidatos, também permitem um fluxo diferenciado de comunicação, tal qual Aldé et al. (2015) chamam de exposição acidental, principalmente quando se compara com o caso dos websites. Ainda que Norris (2003) ressalte que a internet agrega eleitores já interessados em política, "pregando para convertidos", outros autores salientam a possibilidade de uma comunicação segundo o modelo two-step flow (Vaccari e Valeriani, 2013) em que há uma comunicação direta por meio de quem tem interesse prévio no candidato, mas também um contato indireto que atinge os amigos dos apoiadores por meio do redirecionamento de mensagens. Essa lógica supõe o aumento do alcance deste conteúdo transmitido via redes sociais, na medida em que é possível curtir, comentar e compartilhar as postagens.

Utz (2009) argumenta, neste mesmo sentido, que as redes sociais têm maior potencial de atingir diferentes usuários em comparação com os sites, pois fornecem exposições não previstas com conteúdo de campanha advindos dos perfis dos candidatos. Portanto, ainda que se considerem as ponderações de Norris (2003), acredita-se que as redes sociais e suas dinâmicas permitem um alcance do conteúdo, sem necessariamente grandes exigências do eleitor/internauta como é o caso dos sites que pressupõem o acesso específico às páginas.

No Brasil, o uso da internet como ferramenta de comunicação política em períodos eleitorais é mais recente, sendo a eleição de 2002 uma das primeiras a serem estudadas (Aldé, 2004). Parte significativa da produção da literatura brasileira envolvendo campanha e novas mídias se divide em dois grandes grupos: 1) aquele que centram os estudos no conteúdo gerado na rede; e 2) o que reúne os pesquisadores que têm por objetivo investigar o papel da internet como ferramenta de debate/participação. A presente 
pesquisa se encaixa na primeira abordagem, e se justifica por fornecer dados empíricos acerca de como os candidatos se comportam no Facebook durante a campanha eleitoral.

Em termos da produção específica sobre internet, grande parte da literatura brasileira está centrada no uso dos websites dos candidatos como ferramenta de campanha (Massuchin e Tavares, 2015; Massuchin, 2014; 2013; Braga e Nicolás, 2011). No entanto, estudos recentes têm voltado a atenção para investigar o papel das redes sociais no processo eleitoral, como o Twitter (Aggio, 2016; Marques, Aquino e Miola, 2014; Rossetto, Carreira e Almada, 2013; Cervi e Massuchin, 2011) e Facebook (Murta e Mariano, 2015; Tavares e Massuchin, 2015; Aggio e Reis, 2015; Gonçalves e Ferreira, 2013). Sobre o avanço nos estudos, Williams e Gulati (2013) apontam que com a ampla difusão do Facebook, o próximo passo para os pesquisadores é examinar e explicar as diferenças no uso e performance da campanha online, a fim de entender de que maneira os candidatos estão utilizando a nova ferramenta nas campanhas. E é justamente neste ponto que se insere este trabalho.

\section{Estratégias online de comunicação política pelo Facebook}

Da mesma forma que os veículos tradicionais, a internet também apresenta atualização de conteúdos dotados de estratégias eleitorais ${ }^{2}$. Segundo Marques e Sampaio (2011), as campanhas têm o objetivo de convencer e não apenas de informar, portanto parte-se do pressuposto de que o Facebook também é usado ao longo da

\footnotetext{
${ }^{2}$ Este trabalho analisa as diferentes formas de apropriação do Facebook nas campanhas, mas ressalta-se que não há objetivo de relacionar uso da rede social com resultado eleitoral. Ainda que haja estudos sobre o tema, não é esta a intenção desta pesquisa, a qual está preocupada com os usos por parte da elite política e não com os resultados eleitorais.
} 
campanha - mesmo que de modo indireto - para convencer o eleitorado e para isso apresenta determinadas estratégias em seu conteúdo informativo. As pesquisas de Aggio e Reis (2015) e de Assunção et al. (2015) também se preocupam com o conteúdo disponibilizado nas redes sociais a partir de suas estratégias.

As estratégias foram divididas em duas partes, sendo que algumas delas são adaptadas de outros espaços tradicionais, enquanto outras são descritas como típicas das campanhas online $e^{3}$. As estratégias da rede, em sua maioria, estão voltadas para a proximidade com 0 eleitor, a mobilização (Williams e Gulati, 2009) e o engajamento (Bor, 2013) sob uma nova perspectiva. Por outro lado, nem todas as estratégias são inovadoras e podem funcionar como adaptações de outros espaços, como da campanha televisiva, por exemplo. Neste caso, destaca-se a disseminação de informação, a campanha negativa e a proposição de políticas incluídas nesta análise. Para criar determinados perfis de uso e apropriação das redes, Bor (2013) apresenta os principais pontos destacados por organizadores das campanhas como as principais finalidades deste espaço. Abaixo são elencadas algumas dessas estratégias, tanto inovadoras quanto tradicionais, que posteriormente são observadas na análise dos dados $^{4}$.

1) Disseminação de informação: As campanhas eleitorais são os momentos em que os eleitores buscam informação política

\footnotetext{
3 As estratégias não são excludentes, sendo que podem aparecer juntas nas postagens. O objetivo de fazer uma separação, ainda em termos teóricos, é salientar que algumas características são consideradas como "típicas" da internet enquanto outras são típicas dos meios tradicionais e apenas foram adaptadas ao novo espaço de campanha.

4 Ressalta-se que na análise as características elencadas aqui são subdivididas e ampliadas na medida em que novas características também foram encontradas no conteúdo analisado. É o caso, por exemplo, da distinção entre engajamento online e offline. Também há diferenças para a análise do ataque aos adversários, ataque a administração e defesa de ataques. Portanto, aqui na discussão teórica apresentam-se as características e estratégias mais abrangentes, que serão mais bem definidas na análise, conforme a necessidade.
} 
para decidir o voto. E, segundo Bor (2013), da mesma forma que outros espaços, a internet e as redes sociais também são usadas para disseminar informação. No entanto, os conteúdos podem ser ora temáticos - enfatizando o debate ora mais voltados para a própria campanha, com informações semelhantes à metacampanha (Albuquerque, 1999), principalmente tratando da agenda do candidato.

2) Proposição de temas/políticas: Embora a imagem tenha sido uma característica bastante relevante das campanhas modernas (Cervi e Massuchin, 2011), o caráter temático e propositivo ainda tem destaque enquanto estratégia de discurso eleitoral. Os candidatos possuem um projeto/plano de governo e uma das formas de popularizar suas propostas nas mais diversas áreas de políticas públicas é por meio da propaganda eleitoral, enfatizando suas ações futuras e destacando a agenda programática/propositiva. Como define Albuquerque (1999), a discussão de problemas políticos encontra-se dentre as funções da propaganda eleitoral.

3) Campanha negativa: Esta é uma característica também típica das campanhas modernas e que caracteriza o pleito americano (Borba, 2013), ainda que já seja marca de várias campanhas brasileiras. No caso das redes sociais, Bor (2013) concluiu após uma pesquisa com os produtores de campanhas eleitorais, que as mídias sociais não servem para tratar de aspectos negativos e sim positivos. Portanto, não seria o espaço mais adequado para tal estratégia, como mostrou Aggio e Reis (2015), que perceberam o baixo uso das redes para tal estratégia. No entanto, uma análise do Twitter feita por Assunção et al. (2015) observou que 14\% das 
mensagens do perfil auxiliar de Marcelo Freixo (PSOL), na campanha carioca para governador, continham ataques diretos a outros adversários.

4) Engajamento e mobilização: A pesquisa de Bor (2013) identificou que uma das funções das redes é o engajamento, envolvendo cidadãos na campanha e encorajando outros participantes. Essa postura das redes sociais foi observada pela pesquisa de Assunção et al. (2015) na campanha de Freixo, que continha posts sobre trabalho voluntário e envolvimento. Também eram nítidas as chamadas para manifestação de rua e não apenas a presença ativa nas redes online.

5) Interação com os eleitores: Ainda que a presença desta característica tenha relação com a situação do candidato na disputa, Assunção et al. (2015) perceberam o alto índice de uso de interação aberta e ousada por parte de Freixo, diferentemente do caso de Eduardo Paes (PMDB), candidato com maiores chances, que fez uma campanha menos interativa e bastante fechada nas redes sociais. Isso tem relação com a proposição de Stromer-Galley (2000) sobre o porquê de os candidatos evitarem a interação, ainda que isso tenha evoluído nas últimas campanhas. 0 mesmo foi retratado por Bor (2013) ao falar que a grande quantidade de mensagens é usada como justificativa pelas equipes de candidatos para explicar a ausência de interação, onde a rede não é usada para conversar com eleitores.

As cinco principais modalidades de estratégias apresentadas aqui combinam categorias advindas das mídias tradicionais e online. Elas podem ser empregadas de diversas formas na campanha na rede, 
combinadas ou não umas com as outras, dependendo dos objetivos que cada candidato pretende atingir com aquele conteúdo. A maneira como elas foram utilizadas na campanha presidencial de 2014 será detalhada no tópico a seguir.

\section{Metodologia e apresentação das variáveis}

Os dados analisados a seguir compõem uma amostra referente ao período de 6 de julho a 4 de outubro de 2014, que representa todo o primeiro turno das eleições presidenciais daquele ano. A coleta foi viabilizada por meio do aplicativo Netvizz, disponibilizado no próprio Facebook ${ }^{5}$. A partir dela, chegou-se a um banco de dados com o total de 1.081 posts de Dilma Rousseff; 863 de Eduardo Campos/Marina Silva; e 747 posts de Aécio Neves. Para a análise, optou-se por fazer uma amostra representativa do universo ${ }^{6}$, sendo esta calculada a partir do nível de confiança de 95\%. Ao final, a codificação dos dados foi feita tendo como base 283 posts para Dilma Rousseff; 266 para Eduardo Campos/Marina Silva ${ }^{7}$; e 254 para Aécio Neves.

A metodologia empregada na análise dos casos selecionados é a quantitativa de análise de conteúdo, visto que a pesquisa busca

\footnotetext{
${ }^{5} \mathrm{O}$ aplicativo disponibiliza opção de coletar apenas os posts feitos pela página e também aqueles publicados pelos seguidores. Optou-se por salvar apenas o conteúdo produzido pelos administradores da página oficial do candidato, visto que busca-se estudar as estratégias utilizadas na comunicação eleitoral nessa plataforma. Há ainda um banco com todas as interações produzidas nestes posts, que deve ser trabalhado na etapa seguinte desta pesquisa.

${ }^{6}$ Para determinar o tamanho da amostra, utilizou-se a fórmula para universo finito: $\mathrm{n}$ $=\mathrm{N} . p \cdot q \cdot \mathrm{Z}^{2} / \mathrm{p} \cdot \mathrm{q} \cdot \mathrm{Z}^{2}+(\mathrm{N}-1) \cdot \mathrm{e}^{2}$. Após saber o número mínimo de casos para se ter dados com $95 \%$ de confiança, aplicou-se ao banco original a função "simple random" para selecionar aleatoriamente os posts a serem utilizados.

${ }^{7}$ A partir daqui vamos nos referir apenas à Marina Silva. Apesar de os dados combinarem o período onde Eduardo Campos ainda era o candidato (do dia 6 de julho a 13 de agosto), das 13 semanas de campanha, Marina ocupou a posição de candidata em 11. Portanto, o conteúdo demonstrado refere-se majoritariamente à campanha desenvolvida por ela.
} 
trabalhar com um grande número de casos e se propõe a identificar padrões (Cervi, 2009) nas estratégias da campanha no Facebook dos candidatos. O livro de códigos utilizado para fazer a categorização dos posts foi desenvolvido pelas autoras, baseado em metodologias utilizadas para analisar outras ferramentas, como a televisão, jornal e sites (Figueiredo et al., 1998; Albuquerque, 1999; Massuchin e Tavares, 2015). Além disso, foram incluídas algumas variáveis que dizem respeito especificamente à internet (Stromer-Galley, 2000; Bor, 2013; Assunção et al., 2015). O livro de códigos apresenta uma série de variávies ${ }^{8}$, mas para este estudo optou-se por restringir a análise às seguintes, respeitando os objetivos e as hipóteses de trabalho: quantidade de postagens e estratégias empregadas nos posts, com destaque especial à agenda e ao engajamento online/offline/financeiro.

O número de posts publicados pelos candidatos ao longo dos três meses de campanha indica se há diferenças ao longo do tempo ou se o nível de publicação se mantém homogêneo mesmo com a proximidade da data da eleição. As estratégias, que são variáveis dummy, de presença ou ausência, mostram quais foram adotadas naquela publicação. Ressalta-se que um único post pode apresentar várias estratégias, conforme seu tamanho e conteúdo. Embora o livro de códigos seja composto por 21 tipos de estratégias ${ }^{9}$, para este artigo optou-se em dar mais atenção - comparando as diferenças

\footnotetext{
${ }^{8}$ Algumas delas que não aparecem neste estudo são: quantidade de curtidas em posts, comentários, compartilhamentos, engajamento, temática e apelo.

9 Ao todo, são 21 estratégias possíveis: agenda, apoio de celebridades/políticos ao candidato; apoio de celebridades/políticos ao partido/ apoio de eleitores; ataque aos adversários; defesa de ataques; informativo; ênfase em realização; pesquisa de opinião; propositivos; assuntos institucionais; ataque à administração em curso; discurso de vitória; incentivo ao engajamento online; incentivo ao engajamento offline; apoio financeiro; assuntos pessoais; presença de links de outros sites; spots; programas extraídos do Horário Gratuito de Propaganda Eleitoral (HGPE); e outros, quando não se enquadra em nenhuma das anteriores.
} 
entre os candidatos - àquelas ligadas à agenda e aos tipos de engajamento e mobilização (online, offline e apoio financeiro).

A estratégia "agenda" foi considerada em publicações em que o candidato faz referência à sua agenda de campanha, ou seja, onde estaria nos próximos dias ou que lugar havia visitado anteriormente. Um exemplo do uso desse tipo de estratégia é: “A presidenta Dilma Rousseff participa, nesta terça, em Caracas, da 46 Cúpula do Mercosul”; ou então: “Aécio Neves estará hoje em Niterói (RJ). Ele chega à estação das Barcas às 10h20".

Sobre a estratégia de incentivo ao engajamento e mobilização online, foram encaixados todos os posts onde o candidato incentivava algum tipo de engajamento do leitor, desde o mais simples, como "leia mais em"; "acesse nosso plano de governo"; "acompanhe ao vivo e compartilhe"; "assista nosso programa que foi ao ar hoje", até aquelas mais engajadas como "mude sua foto e mostre seu apoio à nossa campanha"; "mande suas perguntas para o candidato com a hashtag...". Trata-se de postagens em que o objetivo é conquistar o eleitor e chamá-lo para engajar-se na campanha, atuando ou contribuindo de alguma forma. Uma categoria semelhante também aparecia nos estudos sobre HGPE, mas aqui a mesma é atualizada para a internet.

Por outro lado, os posts que incentivavam algum tipo de engajamento fora da internet foram categorizados como "incentivo ao engajamento offline". Alguns candidatos podem usar a rede social para pedir que os eleitores atuem como 'líderes de opinião' e ajudem a disseminar informações em outras esferas e até mesmo tentar convencer outras pessoas a votarem. Seguem alguns exemplos: "participe da caminhada junto com o candidato"; "no próximo domingo, vá vestido de verde e amarelo"; "transforme sua casa em 
um comitê do candidato". Estes são incentivos feitos nas redes sociais, mas que têm relação com o mundo offline, ou seja, onde o internauta é chamado para atuar fora da internet. Por fim, o "apoio financeiro" refere-se a postagens onde há pedido explícito de doação financeira por parte dos eleitores à campanha do candidato. Essa também é considerada uma das funções da rede, segundo a literatura sobre a campanha de Obama (Gomes et al., 2009; Leuschner, 2012).

Vale ressaltar que como grande parte das postagens era híbrida, ou seja, apresentava mais de um elemento - como foto e texto; texto e vídeo, texto e áudio; texto e folder -, foi considerada a peça como um todo para fins de análise. Isso significa que o conteúdo do texto e vídeo, por exemplo, foram levados em consideração no momento de categorizá-lo, de maneira conjunta. Passa-se agora à apresentação e discussão dos dados.

\section{Panorama geral das postagens e estratégias empregadas}

A primeira informação fornecida nesta análise diz respeito à quantidade total de postagens feita pelos três candidatos - Dilma Rousseff, Aécio Neves e Marina Silva - de maneira agregada. Por meio desses dados longitudinais tem-se um panorama do número de postagens realizadas ao longo das 13 semanas de campanha, conforme indica o Gráfico 1. 


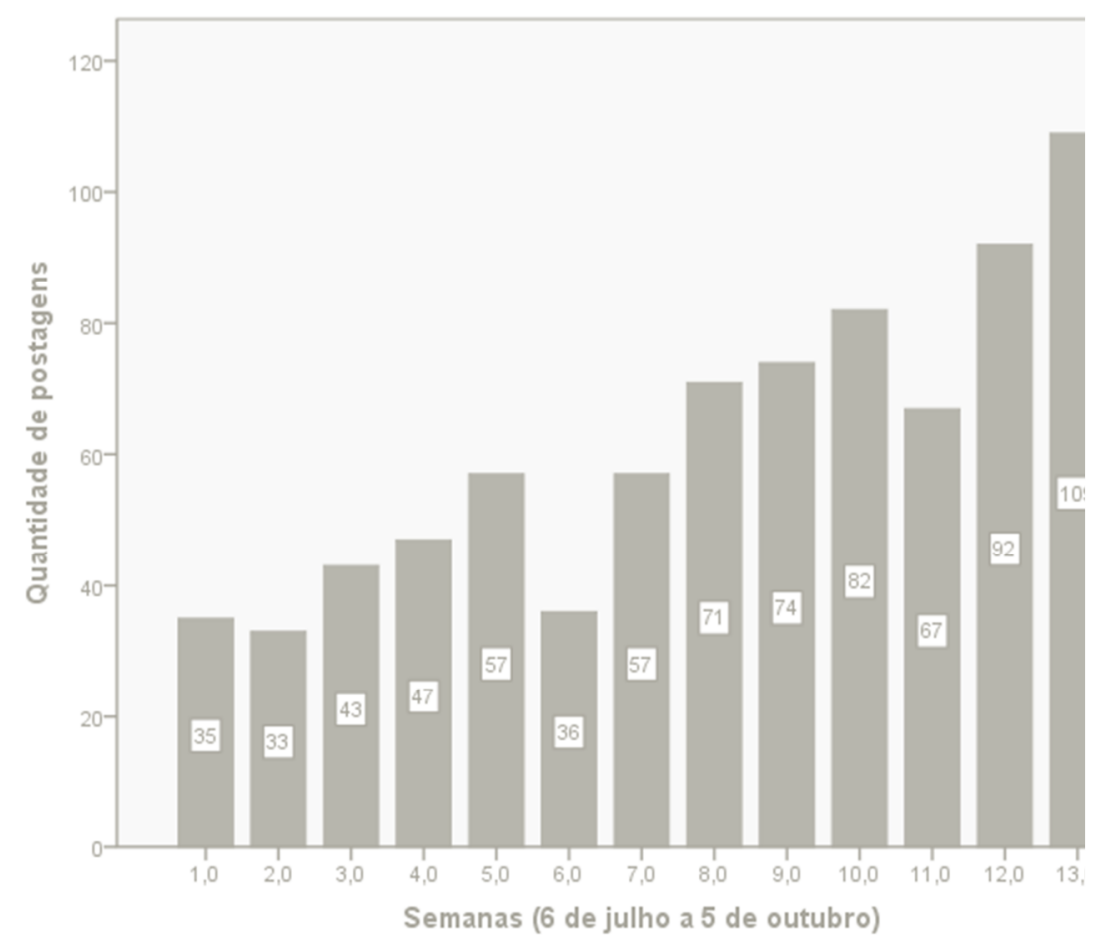

Fonte: As autoras (2015)

Observa-se que há uma tendência de crescimento no número de postagens ao longo do tempo, o que tem relação com o aumento da necessidade de informação por parte do eleitorado para decidir o voto e da possibilidade que os candidatos possuem de disputarem espaço com os oponentes, também na esfera online, no período mais decisivo que são as últimas semanas. Bor (2013) salienta esta importância das redes enquanto fonte de informação e os dados mostram que elas também aumentam a quantidade de informação disponível. Somando os três candidatos, na primeira semana de campanha foram observados 35 posts, terminando com 109 ao final do primeiro turno. Isso demonstra que há uma tendência em intensificar a campanha na rede social conforme o pleito se aproxima. 
Há apenas uma semana onde se verifica queda substantiva na quantidade: a sexta; e uma leve diminuição no número de posts na semana 11. A possível explicação para o primeiro caso é que o período corresponde à morte de Eduardo Campos. Foi um momento atípico, já que houve a necessidade de escolher um novo candidato para dar continuidade ao processo. A então ex-candidata a vice, Marina Silva, assume a cabeça de chapa e passa a ser candidata oficial pelo PSB e dá continuidade ao pleito. Com esta exceção, a campanha no Facebook foi intensificada ao longo da campanha, expressando que a rede segue a necessidade de informação dos eleitores e disponibiliza mais conteúdo neste espaço (Karlsen, 2009). Ao mostrar que aumentam as postagens, ainda que seja em um canal de propaganda do próprio candidato, também representa mais informação disponível e corrobora com a ideia de que a internet, além de espaços interativos, tem conteúdo e informação política.

Ainda que os dados anteriores demonstrem que há crescimento na quantidade de publicação ao longo do tempo, não se sabe até então se os três candidatos se comportaram de maneira semelhante no que diz respeito ao processo de alimentar sua rede social ao longo das 13 semanas analisadas. 


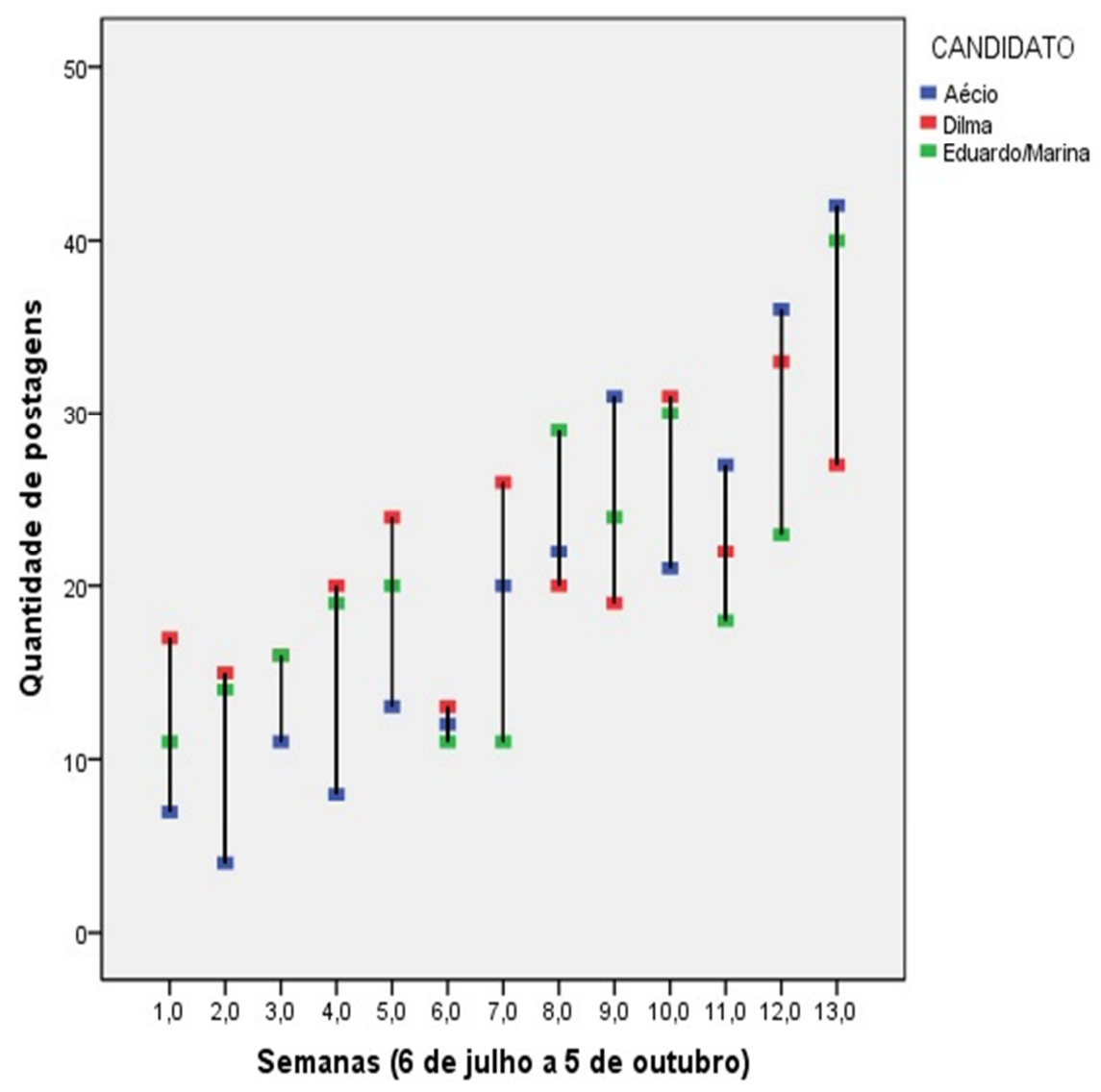

Fonte: As autoras (2015)

Com o gráfico é possível observar que a tendência de aumento das publicações é identificada para todos os candidatos, se comparadas as primeiras e últimas semanas, mas com intensidade diferente para cada um deles. Na primeira semana, Dilma foi a candidata que mais fez postagens, chegando perto da casa dos 20, seguido de Eduardo Campos/Marina Silva, que publicou pouco mais que 10 vezes, e Aécio Neves, que ficou abaixo das 10 publicações semanais. Quando se observa a última semana, verifica-se que o candidato do PSDB intensificou a presença no Facebook, totalizando mais de 40 
postagens no período, assim como Marina Silva, que somou quase 40 postagens. Dilma Rousseff, ao contrário, diminuiu sua presença na rede social nessa última semana de campanha em relação à anterior (12 semana), publicando em torno de 25 posts. A candidata começa com pouco mais de 15 e não passa de 35 postagens nas demais semanas. Percebe-se, com esse gráfico, que Dilma Rousseff começou atuando mais do que seus concorrentes no Facebook, mas que da oitava semana em diante ficou mais contida.

Aécio Neves e Marina Silva não mantiveram tendência de publicação: a quantidade de postagens variou bastante ao longo de todo o primeiro turno para os dois candidatos. 0 que se verifica, no entanto, é que Aécio Neves começou a campanha com o menor número de postagens entre os três concorrentes - o que foi verificado até a quinta semana; e foi o que mais publicou nas últimas três semanas do pleito, o que indica uma valorização da rede, pois o candidato do PSDB intensificou sua presença nela.

Eduardo Campos/Marina Silva manteve tendência de crescimento na quantidade de posts até a quinta semana. Nas semanas 6 e 7 , comparado aos outros candidatos, o número de posts foi bem menor, talvez pelo trâmite da troca de candidatos, decorrente da morte de Eduardo Campos. A partir da oitava semana, Marina Silva também oscila bastante, mantendo-se ora entre a candidata que mais publica (como aconteceu na oitava semana), e em outros momentos como a que menos publica (semanas 11 e 12). No entanto, na última semana antes do primeiro turno, a candidata do PSB também aumentou sua presença no Facebook, chegando próxima de 40 posts - maior número de publicação desde que iniciou a campanha.

Dilma Rousseff, por outro lado, fez menos de 25 publicações na última semana antes da votação, embora tenha se mantido mais 
estável em relação aos demais. Mas todos, de modo geral, intensificam o uso do Facebook ao longo do tempo, o que torna a ferramenta mais relevante no cenário de disputa, seja pelo aumento do número de seguidores ou pelo fortalecimento da ferramenta ao lado das demais formas de campanha.

Os gráficos mostrados até aqui indicam que a rede social cresce em importância conforme a campanha se desenvolve, principalmente, nos casos de Aécio Neves e Marina Silva. No entanto, além de observar a quantidade de postagens, é preciso observar para que tal espaço é utilizado, sabendo-se que o mesmo incorpora a propaganda dos candidatos. Há estratégias que são empregadas nesses conteúdos publicados, a fim de convencer o eleitor, assim como se dá na televisão, no rádio e nas formas tradicionais de campanha eleitoral (Jardim, 2004). Portanto, a tabela 1 apresenta as estratégias empregadas pelos candidatos na campanha no Facebook de 2014.

Tabela 1: Estratégias utilizadas nas postagens do Facebook $^{10}$

\begin{tabular}{l|l|l|l}
\hline Estratégias & $\mathrm{N}$ & $\%$ & $\%$ Casos \\
\hline Agenda/informação da campanha & 250 & $12,8 \%$ & $\mathbf{3 1 , 2 \%}$ \\
\hline Apoio ao candidato & 90 & $4,6 \%$ & $11,2 \%$ \\
\hline Apoio ao partido & 7 & $0,4 \%$ & $0,9 \%$ \\
\hline Apoio de eleitores & 30 & $1,5 \%$ & $3,7 \%$ \\
\hline Ataque aos adversários & & & \\
\hline
\end{tabular}

10Ressalta-se que a última coluna da tabela "fecha" o percentual em mais de $100 \%$ porque se trata do agrupamento de variáveis que podem aparecer de forma concomitante nas postagens. 


\begin{tabular}{|c|c|c|c|}
\hline Defesa de ataques & 29 & $1,5 \%$ & $3,6 \%$ \\
\hline Informação/notícia alheia a campanha & 121 & $6,2 \%$ & $15,1 \%$ \\
\hline Realizações do candidato & 112 & $5,7 \%$ & $14,0 \%$ \\
\hline Pesquisa de intenção de voto/corrida eleitoral & 24 & $1,2 \%$ & $3,0 \%$ \\
\hline Proposição de politicas & 129 & $6,6 \%$ & $16,1 \%$ \\
\hline Institucional & 11 & $0,6 \%$ & $1,4 \%$ \\
\hline Ataque à administração & 38 & $1,9 \%$ & $4,7 \%$ \\
\hline Discurso de vitória & 17 & $0,9 \%$ & $2,1 \%$ \\
\hline Incentivo para engajamento online & 348 & $17,9 \%$ & $43,4 \%$ \\
\hline Incentivo para engajamento off-line & 59 & $3,0 \%$ & $7,4 \%$ \\
\hline Incentivo para apoio financeiro & 6 & $0,3 \%$ & $0,7 \%$ \\
\hline Assuntos pessoais dos candidatos & 7 & $0,4 \%$ & $0,9 \%$ \\
\hline Presença de Links & 460 & $23,6 \%$ & $57,4 \%$ \\
\hline Uso de Spots & 11 & $0,6 \%$ & $1,4 \%$ \\
\hline Uso do HGPE & 34 & $1,7 \%$ & $4,2 \%$ \\
\hline Outro & 105 & $5,4 \%$ & $13,1 \%$ \\
\hline Total & 1949 & $100,0 \%$ & $243,3 \%$ \\
\hline
\end{tabular}

Fonte: As autoras (2015)

No que se refere às estratégias, verifica-se o predomínio de três: a indicação de links (57,4\%), o que delimita uma extensão e ampliação de conteúdo; incentivo ao engajamento online (43,4\%), mostrando a técnica de mobilizar os eleitores; e agenda $(31,2 \%)$. A presença de 
links ${ }^{11}$ foi uma variável criada especialmente para este estudo, pois se verificou, durante a coleta, que muitas postagens continham links que direcionavam para outras plataformas, principalmente ao site do candidato. Como salienta Bor (2013), uma das ações das redes sociais é compartilhar e comunicar mensagens de outros meios de campanha, principalmente fazendo uso de links, integrando outros espaços. Optou-se, então, em colocar como estratégia, pois acreditase que seja uma maneira de incentivar o leitor a buscar informações complementares. De fato, a análise mostra que essa é uma estratégia recorrente no Facebook, o qual é utilizado para integrar a campanha, com a função primordial de levar o leitor até o website do candidato, que seria mais restrito e dependente do interesse dos usuários.

O engajamento online também aparece em quase metade das publicações, o que vai ao encontro com o que Willians e Gulati (2013) e Bor (2013) defendem - que a rede serve para mobilizar, engajar e incentivar o eleitor. Ainda que essa estratégia seja empregada de maneira tímida nas postagens, de um modo bastante simples, ela está presente em mais de $40 \%$ dos casos analisados.

Além de incentivar a busca por informações em outros espaços pelos links, também há a preocupação com o engajamento e mobilização do eleitorado que acessa as redes. Vale ressaltar que, tratando o engajamento e incentivo através da mobilização como um todo, somando o engajamento offline e a arrecadação monetária chega-se a 51,5\% das mensagens com algum tipo de encorajamento dos seguidores para contribuírem com a campanha. Isso leva a crer que os candidatos estão preocupados em fazer com que seus eleitores se engagem - curtindo posts, compartilhando, mostrando seu apoio por meio de fotos personalizadas, etc. Ainda que em níveis diferentes, se

\footnotetext{
${ }^{11}$ A discussão sobre o uso de links não será feita de modo estendido neste artigo, pois está sendo trabalhada de modo separado num estudo complementar, do ponto de vista da complementaridade dos espaços online.
} 
confirma a ideia de Williams e Gulati (2009) quanto ao uso do Facebook para a mobilização e a primeira hipótese proposta na pesquisa.

Dentre as principais estratégias empregadas, a agenda aparece em terceiro, o que tem a ver com o que diziam Williams e Gulati (2009) quanto ao fato de que as redes sociais servem para mobilizar, mas também para falar sobre eventos da campanha, o que demonstra a predominância de informação focada na agenda do candidato e confirma a segunda hipótese da pesquisa, mas com a devida cautela. No início dos estudos sobre comunicação eleitoral online, a literatura indicava que a rede serviria apenas como "caderno eletrônico" (Russmann, 2010; Newell, 2001), ou seja, restringir-se-ia a apenas informar o cotidiano da campanha do candidato e que acontecia em outras esferas. 0 que se verifica na prática e no contexto brasileiro atual referente ao Facebook é que essa orientação restrita não se aplica. Embora esteja entre as principais estratégias, ela se faz presente em pouco mais de $30 \%$ do total de posts, demonstrando que há outros elementos que também são empregados na campanha online, que vão muito além de apenas relatar os acontecimentos cotidianos. Há informação de agenda, mas também engajamento, que seria outra função destacada para as redes sociais, o que define uma mescla entre engajamento e informação como funções preponderantes da rede social analisada.

Destaca-se, ainda, que a agenda pode aparecer em conjunto com outras estratégias informativas e não é a única função da rede, sendo que há outros tipos de informações também sendo oferecidas, tais como os links, os spots, os programas do Horário Gratuito de Propaganda Eleitoral (HGPE), além da proposição de políticas que apareceu em $16 \%$ dos posts analisados. O leque de informações disseminadas pelas redes sociais vai além da agenda de campanha 
propriamente dita, embora esta tenha mais destaque que outros perfis de informação.

Retomando as hipóteses apontadas na introdução do artigo, percebese, por meio dos dados, que ambas se confirmam: o Facebook é usado para encorajar o engajamento e mobilização dos seguidores na campanha dos candidatos, ainda que seja por meio de questões simples, para visitar o site oficial ou mudar o avatar, por exemplo. Isso reforça o que a literatura internacional tem apontado sobre as possibilidades de engajamento (Bor, 2013; Willians e Gulati, 2013). No caso brasileiro, Assunção et al. (2015) também observaram exemplos de mobilização semelhantes por meio das redes na campanha de Marcelo Freixo (PSOL), no Rio de Janeiro, seja chamando para chats, para o offline, para arrecadação, entre outras formas caracterizadas pelos autores. Não se trata, necessariamente, de uma efetiva participação em termos de debate, contribuições, diálogo e deliberação, mas de uma tentativa de que os políticos de tragam os eleitores, através de uma estratégia eleitoral, para mais perto de si e do envolvimento na disputa.

Também se confirma a segunda hipótese, quanto ao uso das redes sociais para disseminar informação política, principalmente de agenda de campanha, algo que apareceu em $30 \%$ das postagens. No entanto, embora esse tipo de informação seja preponderante, há também conteúdos de outras mídias transladados para o Facebook, assim como propostas, ênfase em realizações, notícias, entre outros tipos de conteúdo informativo. Ao que tudo indica, deve-se considerar o Facebook como um espaço de mobilização e incentivo ao engajamento, assim como uma fonte de informação, ainda que majoritariamente sobre a campanha e seus fatos cotidianos. Apesar da confirmação das hipóteses propostas inicialmente de modo agregado, a partir da análise dos dados gerais dos três candidatos, 
não se sabe se a adoção do Facebook quanto a essas duas características - incentivo ao engajamento e informação de agenda ocorre de forma semelhante a todos os candidatos. Para tanto, o tópico seguinte observa as diferenças de modo comparativo para ver o quanto este padrão se dá para todos os candidatos ou não.

\section{Quem usa o Facebook para mobilizar os eleitores?}

Os dados agregados mostraram que a estratégia de incentivo ao engajamento foi bastante utilizada pelos candidatos à presidência em 2014, principalmente aquela que diz respeito à mobilização feita no mundo online, o que corrobora com o que responderam os organizadores de campanha a Bor (2013) sobre para quê usavam o Facebook. No entanto, ainda não se sabe se há diferença entre o que fazem os candidatos na disputa brasileira de 2014. Para detalhar esses dados, a tabela a seguir mostra os dados para cada candidato com auxílio do teste de Chi-Square e dos resíduos padronizados ${ }^{12}$. A candidata Dilma Rousseff foi a que mais empregou essa estratégia entre suas postagens (56,2\%). Eduardo Campos/Marina Silva também recorreram frequentemente a esse tipo de engajamento (42,5\%). Por outro lado, Aécio Neves empregou a estratégia em menos de 1/3 do conteúdo analisado, sendo o candidato menos adepto a ferramenta para engajar os seguidores, fazendo uma campanha mais fechada e menos para envolver seus eleitores.

\footnotetext{
${ }^{12} \mathrm{O}$ teste de Chi-Square é usado para observar a relação entre duas variáveis categóricas. Neste caso, faz-se o cruzamento de cada uma das estratégias com a variável candidato. Já os resíduos padronizados têm a função de identificar, após observar se há relação entre as variáveis, a força entre as categorias das variáveis, observando quais tendem a se aproximar ou se distanciar. Os resíduos, portanto, trazem uma informação complementar ao teste de Chi-Square.
} 
Tabela 2: Incentivo ao engajamento online $\mathrm{x}$ candidatos

\begin{tabular}{|c|c|c|c|c|c|}
\hline \multirow{2}{*}{$\begin{array}{l}\text { Incentivo à } \\
\text { participação } \\
\text { online }\end{array}$} & & \multicolumn{3}{|c|}{ Candidatos } & \multirow[t]{2}{*}{ Total } \\
\hline & & $\begin{array}{l}\text { Aécio } \\
\text { Neves }\end{array}$ & $\begin{array}{l}\text { Dilma } \\
\text { Rousseff }\end{array}$ & $\begin{array}{l}\text { Eduardo } \\
\text { Campos/Marina } \\
\text { Silva }\end{array}$ & \\
\hline \multirow[t]{3}{*}{ Ausência } & $\mathrm{N}$ & 178 & 124 & 153 & 455 \\
\hline & $\%$ & $70,1 \%$ & $43,8 \%$ & $57,5 \%$ & $56,7 \%$ \\
\hline & Res. & 2,8 & $-2,9$ & 0,2 & \\
\hline \multirow[t]{3}{*}{ Presença } & $\mathrm{N}$ & 76 & 159 & 113 & 348 \\
\hline & $\%$ & $29,9 \%$ & $56,2 \%$ & $42,5 \%$ & $43,3 \%$ \\
\hline & Res. & $-3,2$ & 3,3 & $-0,2$ & \\
\hline \multirow[t]{2}{*}{ Total } & $\mathrm{N}$ & 254 & 283 & 266 & 803 \\
\hline & $\%$ & $100 \%$ & $100 \%$ & $100 \%$ & $100 \%$ \\
\hline
\end{tabular}

Fonte: As autoras (2015)

O teste Chi-Square $(37,716)$ ressalta que podemos recusar a hipótese nula de que não há relação entre as variáveis e partir do pressuposto de que alguns candidatos empregam mais esta estratégia do que outros. Para verificar isso, têm-se os resíduos padronizados, válidos quando os valores são maiores ou menores do que +/- 1,96. Dessa forma, observa-se que a candidata Dilma Rousseff apresenta forte relação com a presença dessa estratégia $(3,3)$, enquanto o candidato Aécio Neves é o que tende a empregá-la com menor frequência, conforme mostra o resíduo negativo de $-3,2$. Um exemplo do 
emprego dessa estratégia na campanha de Dilma Rousseff é: "\#DILMADENOVO Curta, compartilhe e faça parte de mais mudanças que a presidenta Dilma quer para o Brasil!". Para a candidata à reeleição, o uso do Facebook para engajar os seguidores na campanha online é mais forte do que para os demais candidatos, principalmente em relação a Aécio Neves. Marina Silva, do ponto de vista estatístico, fica dentro do esperado em relação aos totais, sem resíduos significativos.

Outro tipo de incentivo é o de atuação no mundo off-line. Neste caso, engloba postagens onde os candidatos estimulam os eleitores a se engajarem fora das redes sociais, como na participação em caminhadas e distribuição de material de campanha. Trata-se de uma exigência com maior peso em relação ao compartilhamento de conteúdo, por exemplo, que é uma tarefa simples e menos exigênte. Esta estratégia, ao contrário do caso online, foi bem menos utilizada e apareceu em apenas 7,3\% do total de postagens. Mas ainda assim percebem-se diferenças entre os candidatos quanto a sua utilização. 
Tabela 3: Incentivo ao engajamento offline $\mathrm{x}$ candidatos

\begin{tabular}{|c|c|c|c|c|c|}
\hline \multirow{2}{*}{$\begin{array}{l}\text { Incentivo à } \\
\text { participação } \\
\text { offline }\end{array}$} & & \multicolumn{3}{|c|}{ Candidatos } & \multirow[t]{2}{*}{ Total } \\
\hline & & $\begin{array}{l}\text { Aécio } \\
\text { Neves }\end{array}$ & $\begin{array}{l}\text { Dilma } \\
\text { Rousseff }\end{array}$ & $\begin{array}{l}\text { Eduardo } \\
\text { Campos/ } \\
\text { Marina Silva }\end{array}$ & \\
\hline \multirow[t]{3}{*}{ Ausência } & $\mathrm{N}$ & 226 & 267 & 251 & 744 \\
\hline & $\%$ & $89,0 \%$ & $94,3 \%$ & $94,4 \%$ & $92,7 \%$ \\
\hline & Res. & $-0,6$ & 0,3 & 0,3 & \\
\hline \multirow[t]{3}{*}{ Presença } & $\mathrm{N}$ & 28 & 16 & 15 & 59 \\
\hline & $\%$ & $11,0 \%$ & $5,7 \%$ & $5,6 \%$ & $7,3 \%$ \\
\hline & Res. & 2,2 & $-1,1$ & $-1,0$ & \\
\hline \multirow[t]{2}{*}{ Total } & $\mathrm{N}$ & 254 & 283 & 266 & 803 \\
\hline & $\%$ & $100 \%$ & $100 \%$ & $100 \%$ & $100 \%$ \\
\hline
\end{tabular}

Chi-Square: 7,375 (sig 0,025)

Fonte: As autoras (2015)

Os dados indicam que apenas o candidato Aécio Neves fez o uso dessa estratégia em mais de $10 \%$ de suas postagens, o que está acima da média de todos eles, que era de 7,3\%. Dilma Rousseff e Eduardo Campos/Marina Silva empregaram-na apenas em pouco mais de 5\% do total. Este resultado, destacando a estratégia na campanha de Aécio Neves, pode ser explicado pela campanha que o candidato fez para mobilizar o eleitorado próximo ao final do primeiro turno, incentivando seus eleitores a convencer outros oponentes e a comparecerem com camisas coloridas no dia da votação. Portanto, 
identificam-se aqui exemplos de que o candidato usou a internet para chamar os eleitores a engajarem-se em ações no mundo offline, ainda que isso seja minoritário em relação ao incentivo à participação na campanha online.

A relação entre as variáveis "candidato" e "estratégia" apresenta um Chi-Square de 7,375 (sig 0,025), o que demonstra que é significativa, embora não seja tão forte. Os resíduos confirmam essa orientação, já que Aécio Neves é o único candidato que apresenta valor acima do limite de $+/-1,96$, o que se pode dizer que há uma leve tendência de o candidato empregar essa estratégia mais que seus concorrentes, já que o resíduo foi de 2,2. De toda forma, há que lembrar que a presença do engajamento offline é muito menos presente que o engajamento online na campanha como um todo, o que faz com que Dilma Rousseff continue sendo a candidata que mais se utiliza do Facebook para estimular a mobilização dos eleitores, simpatizantes e seguidores na sua campanha.

Por fim, entre as estratégias que incentivam algum tipo de relação com o eleitor, tem-se a que diz respeito ao apoio financeiro. Essa estratégia tem relação com o que pesquisadores relatam sobre a campanha de Obama, em 2008, quanto ao uso das redes para arrecadação e para incentivar tal ação (Leushner, 2012). A intenção é observar como isso ocorre no Brasil, por meio das redes sociais. 
Tabela 4: Incentivo ao apoio financeiro $\mathrm{x}$ candidatos

\begin{tabular}{|c|c|c|c|c|c|}
\hline \multirow{2}{*}{$\begin{array}{l}\text { Incentivo ao } \\
\text { apoio } \\
\text { financeiro }\end{array}$} & & \multicolumn{3}{|c|}{ Candidatos } & \multirow[t]{2}{*}{ Total } \\
\hline & & $\begin{array}{l}\text { Aécio } \\
\text { Neves }\end{array}$ & $\begin{array}{l}\text { Dilma } \\
\text { Rousseff }\end{array}$ & $\begin{array}{l}\text { Eduardo } \\
\text { Campos/Marina } \\
\text { Silva }\end{array}$ & \\
\hline \multirow[t]{3}{*}{ Ausência } & $\mathrm{N}$ & 254 & 283 & 260 & 797 \\
\hline & $\%$ & $100,0 \%$ & $100,0 \%$ & $97,7 \%$ & $99,3 \%$ \\
\hline & Res. & 0,1 & 0,1 & $-0,2$ & \\
\hline \multirow[t]{3}{*}{ Presença } & $\mathrm{N}$ & 0 & 0 & 6 & 6 \\
\hline & $\%$ & $0 \%$ & $0 \%$ & $2,3 \%$ & $0,7 \%$ \\
\hline & Res. & $-1,4$ & $-1,5$ & 2,8 & \\
\hline \multirow[t]{2}{*}{ Total } & $\mathrm{N}$ & 254 & 283 & 266 & 803 \\
\hline & $\%$ & $100 \%$ & $100 \%$ & $100 \%$ & $100 \%$ \\
\hline
\end{tabular}

Fonte: As autoras (2015)

Observa-se que essa estratégia foi pouco utilizada na campanha online no Facebook durante as eleições de 2014 no Brasil, as quais representam o mais alto grau de modernização e profissionalização das campanhas no país, principalmente em termos financeiros e tecnológicos. Ela apareceu apenas no conteúdo de Eduardo Campos/Marina Silva (2,3\%), que tinham um discurso da "mudança" e levantavam a bandeira de serem independentes e diferentes do que chamavam de "velha política". Como a candidata já havia feito um apelo à arrecadação online em eleições passadas, manteve tal 
característica e foi a única a usar tal estratégia no Facebook. Esta foi uma das maneiras de se diferenciar dos demais adversários. 0 argumento utilizado era de que o financiamento da campanha tinha que ser feito pelos eleitores e não por grandes empresas.

Apesar do discurso da candidata Marina Silva sobre a arrecadação online, fica claro que os eleitores foram bem pouco incentivados a fazer doações à campanha, pelo menos por meio da rede social Facebook, que poderia ter uma boa capilaridade e atuação neste sentido. Por outro lado, este tipo de incentivo pode ter aparecido com maior ênfase no site, por exemplo, que era onde o eleitor podia fazer a doação, de fato.

Torna-se então perceptível que os candidatos focam no engajamento na campanha online em detrimento da offline e do incentivo à doação financeira. Embora duas delas apresentem percentual baixo de presença, no valor agregado - somando-se os três tipos de mobilização na campanha - verifica-se que há grande presença desse tipo de estratégia no conteúdo produzido para Facebook. Os testes mostraram que Dilma Rousseff possui relação mais forte com a mobilização online; Aécio Neves com a offline e Eduardo Campos/Marina Silva com o incentivo ao apoio financeiro, ainda que os dois últimos tenham bem menos preponderância ante todas as estratégias empregadas. De modo geral, os dados reafirmam a hipótese do uso das redes para incentivar o engajamento e mobilizar os eleitores, mas os candidatos exploram cada uma das estratégias de forma diferente. 


\section{Cadê a agenda que estava aqui?}

Os primeiros estudos sobre campanha eleitoral online defendiam que a internet serviria apenas para informar os eleitores dos compromissos de campanha do candidato. No entanto, como os primeiros dados deste artigo indicaram, essa ideia já pode ser considerada superada, pois há outras estratégias bastante presentes nas postagens para além da agenda do candidato. Outros trabalhos já identificaram a mesma tendência em plataformas diferentes, como é o caso de Massuchin (2014), que percebe maior informação propositiva de campanha nos websites eleitorais. Ainda que dados anteriores tenham indicado o uso dessa estratégia em pouco mais de $30 \%$ das postagens, o que está mesclado com o incentivo à mobilização e também com outras estratégias, a tabela a seguir mostra o quanto a agenda de campanha foi empregada na campanha de cada candidato. 
Tabela 5: Agenda x candidatos

\begin{tabular}{|c|c|c|c|c|c|}
\hline \multirow{2}{*}{$\begin{array}{l}\text { Incentivo ao } \\
\text { apoio } \\
\text { financeiros }\end{array}$} & & \multicolumn{3}{|c|}{ Candidatos } & \multirow[t]{2}{*}{ Total } \\
\hline & & $\begin{array}{l}\text { Aécio } \\
\text { Neves }\end{array}$ & $\begin{array}{l}\text { Dilma } \\
\text { Rousseff }\end{array}$ & $\begin{array}{l}\text { Eduardo } \\
\text { Campos/Marina } \\
\text { Silva }\end{array}$ & \\
\hline \multirow[t]{3}{*}{ Ausência } & $\mathrm{N}$ & 157 & 211 & 185 & 553 \\
\hline & $\%$ & $61,8 \%$ & $74,6 \%$ & $69,5 \%$ & $68,9 \%$ \\
\hline & Res. & $-1,4$ & 1,2 & 0,1 & \\
\hline \multirow[t]{3}{*}{ Presença } & $\mathrm{N}$ & 97 & 72 & 81 & 250 \\
\hline & $\%$ & $38,2 \%$ & $25,4 \%$ & $30,5 \%$ & $31,1 \%$ \\
\hline & Res. & 2,0 & $-1,7$ & $-0,2$ & \\
\hline \multirow[t]{2}{*}{ Total } & $\mathrm{N}$ & 254 & 283 & 266 & 803 \\
\hline & $\%$ & $100 \%$ & $100 \%$ & $100 \%$ & $100 \%$ \\
\hline
\end{tabular}

Fonte: As autoras (2015)

Embora não seja finalidade última da campanha online em redes sociais, a agenda ainda integra boa parte das publicações dos candidatos. O destaque, neste caso, é de Aécio Neves, que empregou a estratégia em quase $40 \%$ do seu conteúdo divulgado no Facebook, explorando mais a ferramenta para falar sobre o cotidiano e relação aos seus concorrentes. Eduardo Campos/Marina Silva apresentou a agenda em 30,5\% e Dilma Rousseff em 25,4\%. Os valores são bem menores que os do candidato do PSDB que chegou a $38,2 \%$ das postagens com esse tipo de informação. O teste Chi-Square mostra 
que a relação entre estratégia e candidato é de 10,231, sendo, portanto, significativa. Com os resíduos, podemos verificar que Aécio Neves está mais inclinado a utilizar a estratégia, já que o valor apresentado é de 2,0 positivo. Claro que esta é a forma mais fácil e tradicional de falar da campanha e dar visibilidade ao candidato de modo rápido e sem muitas exigências de elaboração de conteúdo ou ferramentas, por isso tal estratégia segue presente nas redes sociais, inclusive por meio de fotos de passeatas e eventos.

Dilma Rousseff, por outro lado, é a candidata que menos emprega a estratégia em suas postagens, com resultados muito próximos aos de Eduardo Campos/Marina Silva. Esses dados comparativos indicam que os candidatos e suas equipes de campanha estão mais preocupados em empregar outras estratégias no conteúdo disponibilizado ao eleitor, do que se restringirem a apenas contar onde o candidato foi ou irá. Ainda que a "agenda" tenha presença significativa na campanha dos três candidatos, não se pode perder de vista que outras estratégias figuram entre as empregadas, como a mobilização, a proposição de políticas públicas, a ênfase em realizações, entre outras.

\section{Conclusão}

Este artigo teve o objetivo de investigar como foi estruturada a campanha no Facebook dos três principais candidatos à Presidência em 2014: Dilma Rousseff, Aécio Neves e Eduardo Campos/Marina Silva. A partir de amostra representativa do universo total dos posts coletados ao longo do primeiro turno, pode-se chegar a algumas conclusões referentes às hipóteses apresentadas inicialmente. A primeira delas é que o Facebook tem se constituído como um espaço importante dentro do período de campanha, já que a quantidade de 
publicações cresce ao longo do tempo na página dos três candidatos. Isso demonstra a importância da rede enquanto fonte de informação (Bor, 2013), principalmente por atingir até mesmo aquele cidadão que não está em contato direto com o conteúdo da página. Aggio e Reis (2013) lembram que ações interativas com os posts podem ampliar a visibilidade e levar outras pessoas a tomarem inciativas de interação semelhantes, além de colocar em contato com o candidato pessoas que não se predispuseram a buscá-lo num primeiro momento.

Observa-se, também, que as duas hipóteses apresentadas se confirmam: a rede é utilizada para buscar o engajamento do eleitor e também para promover assuntos de campanha, embora esta última numa escala menor do que se pressupunha. Os resultados indicam a predominância das estratégias de mobilização (online e offline) mesclada com a promoção de agenda na campanha feita por meio do Facebook. Dilma Rousseff é a candidata que mais apresenta posts com algum tipo de incentivo à participação online, o que corrobora com os achados de Bor (2013) e Williams e Gulati (2009) de que essa é uma das principais funções da rede para as campanhas eleitorais.

Destaca-se que esse incentivo é feito muitas vezes de maneira simples nas postagens, como pedir para curtir o post, compartilhar, assistir o programa televisivo ou ainda acessar algum link que proporcione mais informações sobre aquilo que está sendo tratado. No que concerne à mobilização offline e de incentivo financeiro, essas estratégias estiveram mais presentes nas páginas de Aécio Neves e Eduardo Campos/Marina Silva, respectivamente. Embora estas últimas duas formas de estímulo ao engajamento sejam características da campanha na rede, conforme apontado por Small (2008), elas não se apresentaram de forma significativa na campanha brasileira estudada neste trabalho. 
Vale ressaltar que a pesquisa considera esse tipo de ação nas redes sociais a partir do viés da estratégia de campanha e não pela discussão da participação, já que como os exemplos indicam, são ações dos partidos e candidatos para chamar a atenção dos usuários da rede, mas que não representam uma participação efetiva, a partir do conceito de participação vindo das teorias da democracia, em que há troca de ideias e pró-atividade dos atores sociais, no que se poderia ser chamado de conversação civil (MARQUES, 2006). Por isso, utiliza-se aqui o termo estratégia de mobilização e/ou incentivo ao engajamento quando se faz referência às estratégias de envolver os seguidores das páginas - e possíveis eleitores - na campanha.

Além da função de mobilização, identificou-se ainda que o Facebook é utilizado para disseminar assuntos de campanha, principalmente os ligados ao cotidiano do candidato, o qual é chamado aqui de “agenda". Aécio Neves é o que mais se utiliza dessa estratégia nas publicações, sendo recorrente em aproximadamente $38 \%$ de suas postagens. Já Dilma Rousseff e Eduardo Campos/Marina Silva relataram os acontecimentos da campanha em 25,4\% e 30,5\%, respectivamente. Ou seja, apesar de comprovar a hipótese, verificase que a estratégia é utilizada em menos de um terço das publicações nos dois últimos casos. Isso significa que embora figure entre as principais estratégias de campanha, não é o que predomina na mensagem geral das postagens. Isso dá uma ideia de que outras estratégias, como apresentação de temas e ênfase em realizações, também aparecem e tornam a campanha mais dinâmica e menos voltada apenas para a informação cotidiana.

Ainda que os resultados apresentados possam ser aprofundados ou expandidos, relacionando outras estratégias, busca-se aqui preencher uma breve parte da lacuna nos estudos sobre campanhas eleitorais no Facebook. As pesquisas sobre essa rede enquanto 
ferramenta de campanha são escassas, tanto no contexto nacional quanto estrangeiro, conforme constatam Aggio e Reis (2013). Esperase, por outro lado, que novos trabalhos se dediquem a pesquisar os conteúdos eleitorais gerados nessa plataforma, a fim de se ter uma visão geral de como a campanha é estruturada e de que maneira dialoga com outros espaços, também em cenários locais e regionais. 


\section{Referências}

AGGIO, C. Campanhas online e twitter: a interação entre campanhas e eleitores nas eleições presidenciais brasileiras de 2010. Revista Famecos, v. 23, n. 1, 2016.

AGGIO, C.; REIS, L. Campanha eleitoral no Facebook: usos, configurações e o papel atribuído por três candidatos eleitos nas eleições municipais de 2012. In: ALDÉ, A; MARQUES, F. Internet e Poder Local. Salvador: Edufba, 2015.

ALBUQUERQUE, A. “Aqui você vê a verdade na tevê”: A propaganda política na televisão. Niterói: MCII, 1999.

ALDÉ, A. Jornalistas e internet: a rede como fonte de informação política. Trabalho apresentado no IV Encontro dos Núcleos de Pesquisa da Intercom, 2004.

ALDÉ, A.; CHAGAS, V.; SANTOS, J. G. Teses e dissertações defendidas no Brasil (1992-2012): um mapa da pesquisa em comunicação e política 2013. Revista Compolítica, v.2, n.3, 2013.

ASSUNÇÃO, A; ALDÉ, A; SANTOS, J. G.; FREIRE, F. Estratégias de campanha política on-line: Marcelo freixo nas Eleições para a prefeitura do Rio de Janeiro em 2012. In: ALDÉ, A.; MARQUES, F. Internet e Poder Local. Salvador: Edufba, 2015.

BOR, S. Using Social Network Sites to Improve Communication Between Political Campaigns and Citizens in the 2012 Election. American Behavioral Scientist, n.7, Jun/2013.

BORBA, F. Rádio e Televisão na Eleição Presidencial de 2010. In: PANKE, L.; GONDO, R. (Org.). HGPE: Desafios e Perspectivas nos 50 anos do Horário Gratuito de Propaganda Eleitoral. São Paulo: Nova Consciência, 2013.

BRAGA, S.; BECHER, A. O uso das mídias sociais é um bom preditor de sucesso eleitoral dos candidatos? Uma análise das campanhas on-line dos vereadores das capitais das regiões Sul, Sudeste e Nordeste do Brasil no pleito de outubro de 2012. In: ALDÉ, A; MARQUES, F. Internet e Poder Local. Salvador: Edufba, 2015.

BRAGA, S.; NICOLAS, M. A. O que a internet agrega às eleições? Um balanço inicial do uso da internet pelos candidatos aos governos estaduais e ao senado federal nas eleições brasileiras de outubro de 2010. IV Congreso WAPOR. Belo Horizonte, 2011.

BRAGA, S. NICOLÁS, M. A; BECHER, A. Clientelismo, internet e voto: Personalismo e transferência de recursos nas campanhas online para vereador nas eleições de outubro de 2008 no Brasil. Opinião Pública, n. 19, 2013.

BRASIL. Presidência da República. Secretaria de Comunicação Social. Pesquisa brasileira de mídia 2015: hábitos de consumo de mídia pela população brasileira. - Brasília: Secom, 2014. Disponível em: <http://www.secom.gov.br/atuacao/pesquisa/lista-de-pesquisasquantitativas-e-qualitativas-de-contratos-atuais/pesquisa-brasileira-de-midia-pbm2015.pdf/view>. Acesso em: 1 de julho de 2015.

CERVI, E. U. Métodos quantitativos nas ciências sociais. In: BOURGUIGNON, J. (Org.). Pesquisa Social: reflexões teóricas e metodológicas. $1^{a}$ ed. Ponta Grossa: Toda Palavra, 2009.

CERVI, E. U.; MASSUCHIN; M. O uso do twitter nas eleições de 2010. Contemporânea (UFBA), V.9, pp.174 - 189, 2011. 
FIGUEIREDO, M., FIGUEIREDO, M., ALDE, A., DIAS, H. e JORGE, V. Estratégias de Persuasão em Eleições Majoritárias: uma proposta metodológica para o estudo da propaganda eleitoral. Série Estudos, Iuperj, 1998.

GOMES, W.; FERNANDES, B.; REIS, L.; SILVA, T. Politics 2.0: a campanha on-line de Barack Obama em 2008. Revista de Sociologia e Política, Curitiba, v. 17, n. 34, 2009.

GONÇALVES, L.; FERREIRA, A. Facebook: a nova ferramenta de campanha eleitoral digital. Revista Panorama, v. 3, n. 1, 2013.

HOLTZ-BACHA, C.; JOHANSSON, B.; LEIDENBERGER, J.; MAAREK, P. J.; JENSEN, T. B.; DYRBY, S. Exploring Affordances of Facebook as a Social Media Platform in Political Campaigning. ECIS 2013 Proceedings. [Paper 43] Atlanta, GA: Association for Information Systems. AIS Electronic Library (AISeL), 2013.

KARLSEN, R. Online e Undecided. Voters and the Internet in the Contemporary Norwegian Campaign. Scandinavian Political Studies, n. 33, pp. 28-50, 2010.

LEUSCHNER, K. The use of the internet and social media in US Presidential campaigns 1992-2012. Project presented to the Faculty of the Undergraduate College of Arts and Letters James Madison University, 56 p, 2012.

MARQUES, F. P. J. A.; MIOLA, E.; AQUINO J. Deputados brasileiros no Twitter: um estudo quantitativo dos padrões de adoção e uso da ferramenta. Revista Brasileira de Ciência Política (Impresso), v. 14, pp. 201-225, 2014

MARQUES, F. P. J. A.; SAMPAIO, R. C. Internet e eleições 2010 no Brasil: rupturas e continuidades nos padrões mediáticos das campanhas políticas online. Revista Galáxia, n. 22, pp. 208-221, 2011.

MARQUES, F. P. J. A. Debates políticos na internet: da perspectiva da conversação civil. Opinião Pública, Campinas, v. 12, n.1, 2006.

MASSUCHIN, M.; TAVARES, C. Q. Modernização das campanhas e estratégias eleitorais: os padrões de uso da internet nas eleições de 2014. In: VI Encontro da Compolítica. Rio de Janeiro, 2015.

Estratégias usadas pelos candidatos na campanha online: um estudo comparativo das eleições de 2012 em capitais brasileiras. In: VI Wapor Latinoamérica. Santiago de Chile, 2014.

.; Quais as funções dos websites durante as campanhas eleitorais? As eleições brasileiras de 2012 e o cenário de Curitiba. II Congreso Internacional en Comunicación Política y Estratégias de Campaña. Toluca, 2013.

MURTA, F.; MARIANO, V. O uso do Facebook por Alessandro Molon durante a campanha de reeleição para deputado federal em 2014. VI Encontro da Compolítica. Rio de Janeiro, 2015.

NORRIS, P. Preaching to the Converted? Pluralism, Participation and Party Websites. Party Politics, v.9, n.1, pp. 21-45, 2003.

ROSSETTO, G.; CARREIRO, R.; ALMADA, M. P. Twitter e comunicação política: limites e possibilidades. Revista Compolítica, n. 3, vol. 2, jul-dez/2013. 
STROMER-GALLEY, J. On-line interaction and why candidates avoid it. Journal of Communication, n. 50, pp. 111-132, 2000.

UTZ, S. The (Potential) Benefits of Campaigning via Social Network Sites. Journal of ComputerMediated Communication, 14, pp. 221-243, 2009.

VACCARI, C; VALERIANI, A. Follow the leader! Direct and indirect flows of political communication during the 2013 general election campaign. New Media \& Society, Sage, pp. 1$18,2013$.

WILLIAMS, C. B.; GULATI, G. Explaining Facebook Support in the 2008 Congressional Election Cycle. Working Papers. Paper 26, 2009.

Social Media and Campaign 2012: Developments and Trends for Facebook Adoption. Social Science Computer Review, v.31, n.5, 2013.

COMP(IITICA

ASSOCIACCÃO BRASILEIRA

DE PESQUISADORES EM

COMUNICACÃO E POLITIICA

Diretoria da Associação/ Director Boara

Presidente | President

Fernando Lattman-Weltman (UERJ)

Vice-Presidente | Vice-President

Arthur Ituassu (PUC-Rio)

Secretária Executiva | Executive Secretary

Kelly Prudêncio (UFPR)

\section{Corpo Editorial / Editorial Board}

Coordenaçäo Editorial | Editorial Coordination Alessandra Aldé (UERJ) \& Maria Helena Weber (UFRGS)

Editores Executivos | Executive Editors

Camilo Aggio (UFBA), Diógenes Lycariäo (UFC), Rafael Cardoso Sampaio (UFPR) \& Viktor Chagas (UFF)

Editoras Assistentes | Assistant Editors

Ana Angélica Soares (FGV), Fernanda Sanglard (UERJ) \& Isabele Mitozo (UFPF)
A Revista Compolítica é uma revista eletrônica da Associação Brasileira de Pesquisadores em Comunicação e Política

[Revista Compolitica is an electronic journal published by the Brazilian Association of Political Communication Scholars]

Ao citar este artigo, utilize a seguinte referência bibliográfica

[To cite this article, please use the following reference]

MASSUCHIN, M. G.; TAVARES, C. Q. Campanha eleitoral nas redes sociais: estratégias empregadas pelos candidatos à Presidência em 2014 no Facebook. In: Revista Compolítica 5 (2), 2015. 
